TecnoLógicas

ISSN-p 0123-7799

ISSN-e 2256-5337

Vol. 21, No. 43, pp. 71-89

Sep-dic de 2018

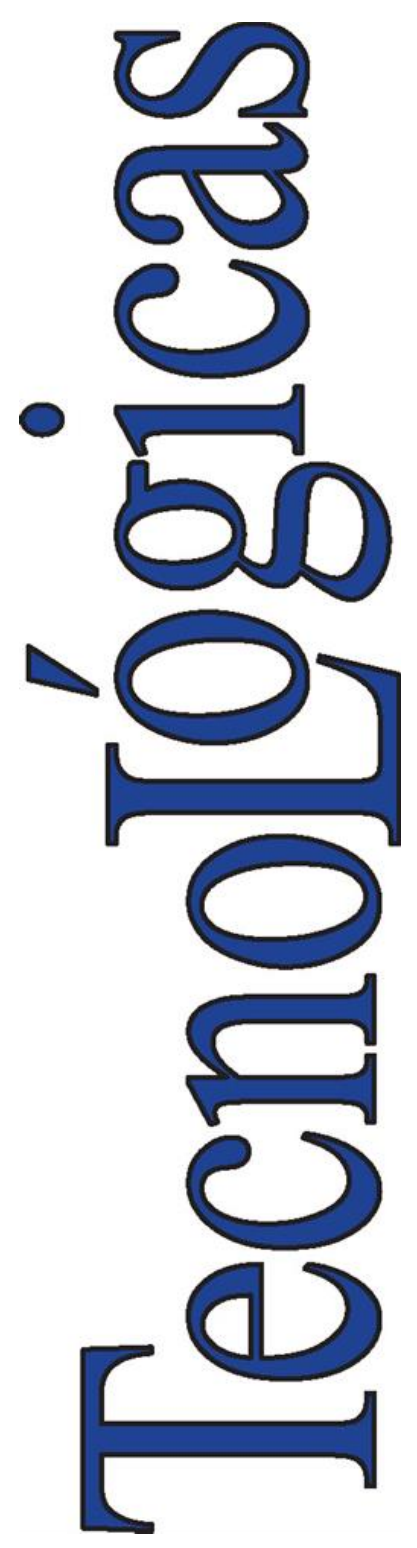

(C) Instituto Tecnológico Metropolitano

Este trabajo está licenciado bajo una Licencia Internacional Creative Commons CC BY-NC-SA

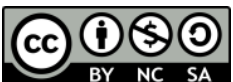

Artículo de Investigación/Research Article

\section{Análisis de factibilidad técnico- económico de microrredes que integran celdas de combustible en zonas no interconectadas de Colombia}

\section{Technical-economic feasibility analysis of micro grids integrating fuel cells in non- interconnected zones in Colombia}

\author{
Daniel González-Montoya ${ }^{1}$, Carlos A. Ramos-Paja ${ }^{2}$, \\ Bernardo A. Potosí-Guerrero ${ }^{3}$, Elkin E. Henao-Bravo ${ }^{4}$, y \\ Andrés Julián Saavedra-Montes ${ }^{5}$
}

Recibido: 11 de mayo de 2017

Aceptado: 10 de mayo de 2018

Cómo citar / How to cite

D. González-Montoya, C. A. Ramos-Paja, B. A. Potosí-Guerrero, E. E. Henao-Bravo y A. J. Saavedra-Montes, Análisis de factibilidad técnicoeconómico de microrredes que integran celdas de combustible en zonas no interconectadas de Colombia. TecnoLógicas, vol. 21, no. 43, pp. 71$89,2018$.

1 PhD. en Ingeniería Automática, Departamento de Electrónica y Telecomunicaciones, Ingeniero de Control, Instituto Tecnológico Metropolitano, Medellín-Colombia,danielgonzalez@itm.edu.co

2 PhD. en Ingeniería Electrónica, Automática y Comunicaciones, Ingeniero Electrónico, Departamento de Energía Eléctrica y Automática, Universidad Nacional de Colombia sede Medellín, Medellín-Colombia, caramosp@unal.edu.co

3 Ingeniero de Control, Departamento de Energía Eléctrica y Automática, Universidad Nacional de Colombia sede Medellín, bapotosig@unal.edu.co

4 MSc. en Ingeniería Eléctrica, Ingeniero Electrónico, Departamento de Mecatrónica y Electromecánica, Instituto Tecnológico Metropolitano, Medellín-Colombia, elkinhenao@itm.edu.co

5 PhD. en Ingeniería Eléctrica, Ingeniero Electricista, Departamento de Energía Eléctrica y Automática, Universidad Nacional de Colombia sede Medellín, Medellín-Colombia, ajsaaved@unal.edu.co 


\section{Resumen}

La necesidad de proveer soluciones energéticas sostenibles para las zonas no interconectadas de Colombia, dependiendo de los recursos renovables disponibles en cada zona, supone un desafío respecto al análisis de viabilidad técnico-económica de las alternativas de solución a través de las microrredes. Este documento tiene como objetivo analizar el impacto técnico-económico de introducir celdas de combustible en la reducción de costos a lo largo del tiempo de vida de una microrred para zonas no interconectadas, empleando el software HOMER. Dicho impacto se evalúa tanto en el diseño técnico de la microrred como en el Valor Presente Neto y en el Costo nivelado de Energía $(\$ / \mathrm{kWh})$. El análisis se realiza a partir de la cuantificación de la demanda de un poblado prototipo, el dimensionamiento y costo de las tecnologías que conforman la microrred para atender la demanda, y la disponibilidad de los recursos renovables solar y eólico de dos zonas localizadas en diferentes latitudes no interconectadas de Colombia. Adicionalmente, se analiza el efecto de introducir las celdas de combustible en el mix energético, resaltando las ventajas obtenidas al comparar cada caso frente a una generación tradicional basada en consumo de Diésel.

\section{Palabras clave}

Celdas de combustible, microrredes, software HOMER, zonas no interconectadas, emisiones de $\mathrm{CO}_{2}$.

\section{Abstract}

The sustainable power solutions provided to non-interconnected zones should be based on the renewable energy resources available in each area. This presents a challenge for the techno-economic feasibility of alternative solutions through micro grids. The objective of this work is to analyze, using HOMER software, the techno-economic impact of introducing fuel cells on cost reduction during the lifetime of micro grids in non-interconnected zones. Such impact is evaluated in the technical design of the micro grid as Present Value and Levelized Cost of Electricity $(\$ / \mathrm{kWh})$. The analysis considers the calculation of the demand of a generic village, the size and cost of the technologies that constitute the micro grid to satisfy the demand, and the availability of solar and wind power in two areas located at different latitudes in Colombia. In addition, the effect of introducing fuel cells into the energy mix was examined. Finally, the advantages were highlighted by comparing each case with traditional generation alternatives based on diesel consumption.

\section{Keywords}

Fuel cells, micro grids, HOMER software, non-interconnected zones, $\mathrm{CO}_{2}$ emissions. 


\section{INTRODUCTION}

La necesidad actual de desarrollar estrategias sostenibles para suplir los requerimientos energéticos de las Zonas No Interconectadas en Colombia (ZNI), ha supuesto un desafío tanto para investigadores como para entidades gubernamentales, en el sentido de ofrecer a estas comunidades un servicio eléctrico asequible, de calidad, económicamente viable, confiable y sobre todo amigable con el medio ambiente. En este sentido, políticas como las establecidas en el plan de desarrollo de las Fuentes de Energía No Convencionales (FENC), que sugieren como estrategia central el uso de estas para asegurar una generación eléctrica confiable en las ZNI [1], dan cabida a las microrredes que permiten aprovechar los recursos renovables de tales zonas. Además de esta, la Ley 1715 de 2014 [2] y la Resolución 0186 de 2012 [3] fomentan el uso de FENC para las ZNI. A pesar de estas políticas, el principal inconveniente es el alto costo de inversión y mantenimiento para proyectos de este tipo, que llevan a concluir su baja viabilidad económica [1], [4], [5]. Este hecho puede ser constatado al emplear un software como HOMER ("Hybrid Optimization for Multiple Energy Resources" por sus siglas en inglés) para realizar el análisis técnicoeconómico de una implementación de la microrred, conformada por fuentes renovables y no renovables para un cierto poblado en Colombia, al tener en cuenta tanto los costos de cada tecnología, como los de importación, transporte y combustibles, los cuales dependen en determinada medida del lugar donde se planea instalar la microrred. Otra variable que también afecta la viabilidad de aplicar este tipo de soluciones es la intermitencia de los recursos renovables [6], ya que cada zona posee su propio patrón de radiación solar y perfil de viento, que puede llegar a ser insuficiente en algunas zonas, afectando la confiabilidad del sistema o incluso restringiendo las alternativas energéticas de generación aplicables al lugar en cuestión [7], [8]. Por lo anterior, se requiere un correcto estudio de prefactibilidad de una instalación basada en este tipo de tecnologías, lo que permitirá determinar si la solución es válida no solo técnicamente, es decir, en cuanto al suministro de la energía eléctrica, sino viable económicamente en comparación con soluciones energéticas tradicionales, como la generación a partir de combustible fósiles [5], [8].

Una alternativa de generación eléctrica que permite reducir estos inconvenientes, debido a su estabilidad, son las celdas de combustible (CC), que, a pesar de ser una tecnología relativamente costosa, su alta eficiencia energética (40-50\%) [9] permite una generación eléctrica más económica [7], [8], [10]-[13]. Asimismo, las CC introducen beneficios ambientales debido a la reducción de emisiones de $\mathrm{CO}_{2}$, además de la posibilidad de cogeneración que ofrecen (CHP "Combined Heat and Power") [14], [15], incrementando la eficiencia energética global del sistema en un 80-90 $\%$ [9], [11], [14] siendo así, otra alternativa a tener en cuenta para suplir las necesidades energéticas en las ZNI a través de las microrredes [10], [12], [13].

Múltiples trabajos reportados en la literatura se centran en realizar estudios técnico-económicos de la viabilidad de este tipo de sistemas en microrredes, determinando así su utilidad para la reducción de costos y disminución de la liberación de gases contaminantes a la atmosfera. Por ejemplo, en [7] los autores proponen un estudio para la integración de $\mathrm{CC}$ en microrredes aisladas, donde el componente técnico es validado mediante el uso de dicha tecnología, dando como resultado que el remplazo de los generadores diésel por CC permiten implementar microrredes eléctricamente viables. Por el contrario, el estudio afirma que la utilidad de los sistemas basados en $\mathrm{CC}$ son económicamente inviables debido a 
los altos costos de instalación y mantenimiento para el año en el cual se realizó el estudio (2006), sin embargo, remarca que, con el decrecimiento de los costos de los componentes de las CC, en los años siguientes la tecnología podría ser viable económicamente.

Otro estudio, presentado en [13], realiza un análisis de la integración de CC con diferentes alternativas renovables para suplir una demanda energética en una comunidad apartada del norte de Italia. Ese análisis concluye que la viabilidad técnico-económica de la integración de CC a microrredes depende estrictamente de los recursos meteorológicos y del perfil de carga que presente la región donde se desee realizar la instalación. Por tanto, sus conclusiones no pueden aplicarse al contexto colombiano.

El trabajo presentado en [4] realiza un análisis detallado del dimensionamiento óptimo de una microrred que se compone de diferentes tecnologías renovables y CC. Ese estudio determina el procedimiento estándar que se debe realizar para diseñar una microrred óptima, tanto para el abastecimiento eléctrico constante de una carga particular, como para garantizar una viabilidad económica en una región apartada. El trabajo presenta además el procedimiento que se debe seguir para llevar a cabo una instalación real de una microrred en un determinado lugar, donde se indican los siguientes pasos:

- Recolección de datos necesarios para cuantificar el recurso renovable de una región (velocidad de viento, radiación solar, etc) y caracterización energética de la instalación (perfil de carga, especificaciones técnicas, etc).

- Selección de tecnologías a implementar dependiendo de los recursos renovables de la región.

- Dimensionamiento de los componentes a partir de técnicas de optimización o software especializado, como HOMER, para determinar una instalación técnicoeconómica óptima.
- Analizar los resultados obtenidos para determinar la mejor solución que pueda ser llevada a una implementación real.

Por lo tanto, este documento presenta un análisis de la viabilidad técnica y económica, realizado a través del software HOMER, de una microrred conformada por fuentes renovables y no renovables, dimensionada para las características de poblados prototipos ubicados en dos latitudes de Colombia que pertenecen a las ZNI [16]. Igualmente, se evalúan y contrastan las distintas configuraciones viables de acuerdo con los recursos renovables solar y eólico presentes en cada zona, para luego incluir la CC en el mix energético y analizar así su impacto técnico en el dimensionamiento óptimo de los elementos, así como su viabilidad económica en la reducción de costos mediante los indicadores de valor presente neto y costo nivelado de la energía $(\$ / \mathrm{kWh})$.

\section{CUANTIFICACIÓN Y DETERMINACIÓN DE LA DEMANDA DE UN POBlado PROTOTIPO}

Para la realización del estudio, se establece la demanda de un poblado hipotético para ser ubicado en dos latitudes diferentes del territorio colombiano, con el objetivo de contrastar la disponibilidad de los recursos renovables frente a la misma demanda. El poblado consta de 50 viviendas con alumbrado público, al cual se establece un perfil de carga de 24 horas.

\subsection{Cuantificación de la demanda de potencia}

Para la cuantificación de la demanda, reportada en la Tabla 1 , se realiza una estimación de las diferentes cargas que una vivienda puede poseer, las unidades y su consumo, de manera similar a como se describe en [17]. Se contempla el uso de un Plan URE (Uso Racional y Eficiente de la 
Análisis de factibilidad técnico-económico de microrredes que integran celdas de combustible en zonas no interconectadas de Colombia

energía) con el uso de bombillas ahorradoras de $15 \mathrm{~W}$ para cada vivienda.

\subsection{Determinación de la demanda - Perfil de carga}

Para la obtención del perfil de carga del poblado, que se presenta en la Fig. 1, se aplica la curva de carga en porcentaje para un servicio de 24 horas, establecida por la CREG (Comisión de Regulación de Energía y Gas) para las ZNI [18], sobre la demanda total cuantificada en el paso anterior.

\section{CARACTERIZACIÓN DEL POTENCIAL ENERGÉTICO RENOVABLE DE LAS ZONAS DE UBICACIÓN DEL POBLADO}

Teniendo en cuenta que el objetivo es contrastar las configuraciones viables de la microrred, de acuerdo con la disponibilidad de los recursos renovables presentes en cada zona a través de HOMER, el poblado se ubica en dos regiones con condiciones ambientales opuestas.

Tabla 1. Cuantificación de la demanda de potencia del poblado. Fuente: autores.

\begin{tabular}{lccc}
\hline & $\begin{array}{c}\text { Potencia } \\
\text { Unitaria (W) }\end{array}$ & Unidades & $\begin{array}{c}\text { Potencia } \\
\text { instalada }(\mathrm{kW})\end{array}$ \\
\hline Bombillas & 15 & 4 & 0.06 \\
Radio & 20 & 1 & 0.02 \\
Refrigerador & 140 & 1 & 0.14 \\
Ventilador & 70 & 2 & 0.14 \\
TV & 120 & 1 & 0.12 \\
Otros & 200 & 1 & 0.2 \\
Total Vivienda & & & 0.68 \\
Total 50 Viviendas & & 15 & 34.0 \\
\hline Alumbrado Público & & & 1.2 \\
\hline D pm a 6 am) & 80 & & $35.2 \mathrm{~kW}$ \\
\hline
\end{tabular}

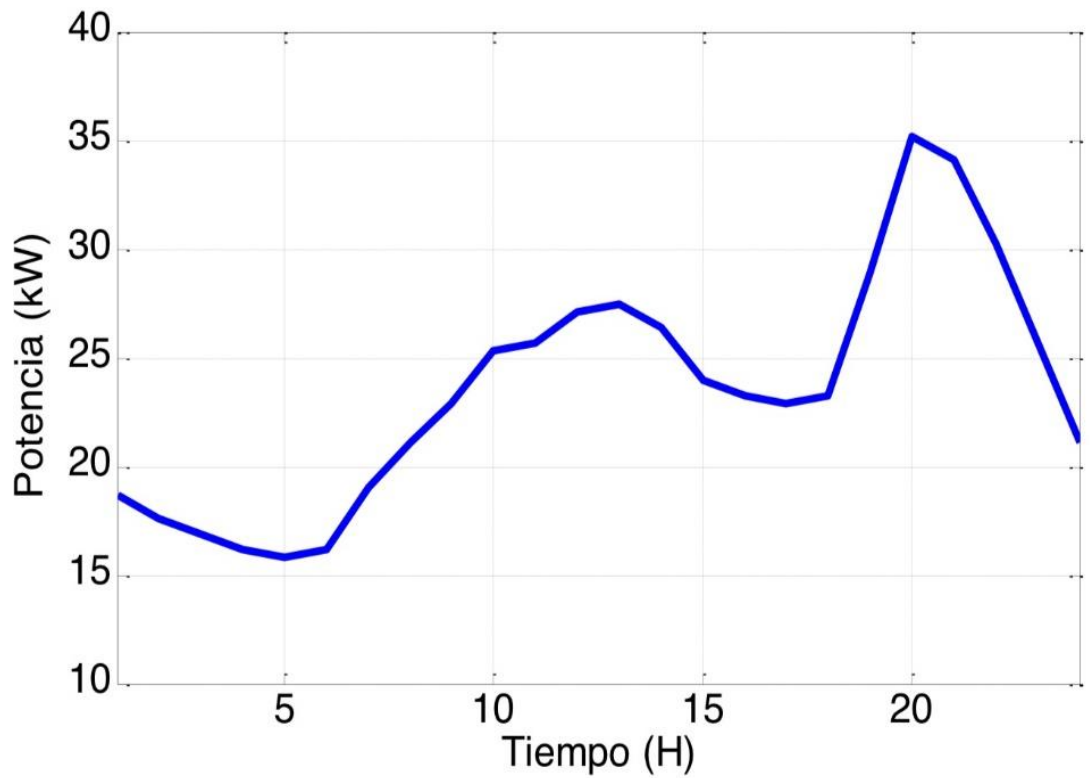

Fig. 1. Perfil de carga de 24 h para el poblado genérico. Fuente: autores. 
Para este estudio, se establece como primera ubicación la localidad de Puerto Bolívar, departamento de La Guajira, la cual posee un potencial solar y eólico alto, debido a que se encuentra en una región árida de alta radiación solar y es barrida por los vientos alisios fuertes, provenientes del mar Caribe. Los potenciales de esta región se reportan en la Fig. 2 y Fig.3. En contraste, la segunda ubicación se establece en la localidad de La Pedrera, departamento del Amazonas, la cual posee un potencial solar y eólico menor, debido a que al estar en la región selvática tropical del Amazonas, y es una zona de convergencia intertropical de los vientos alisios del norte y del sur, la cual presenta mayor temperatura, humedad, con corrientes de aire ascendente que incrementan la nubosidad y por ende las lluvias, reduciendo la disponibilidad de la radiación solar y de vientos para la generación eólica. Estas condiciones se aprecian en la Fig. 4 y Fig. 5. Los datos mostrados en la Fig. 2 a 5 son tomados del software HOMER, el cual a su vez la descarga de la base de datos presentada en [19].

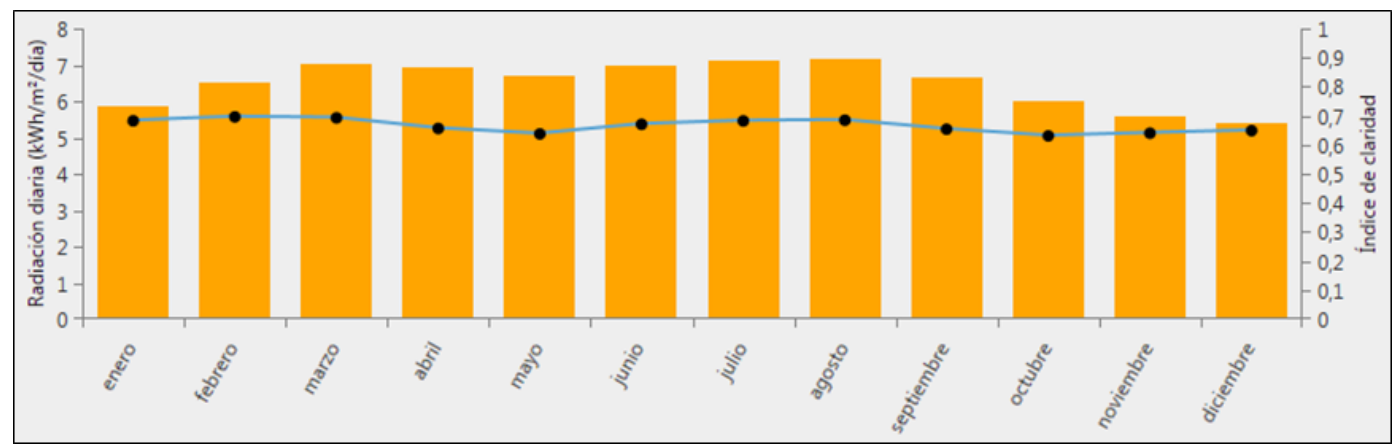

Fig. 2. Recurso solar en HOMER de Puerto Bolívar, La Guajira. Promedio anual: 6.50 kWh/m2/día. Fuente: autores.

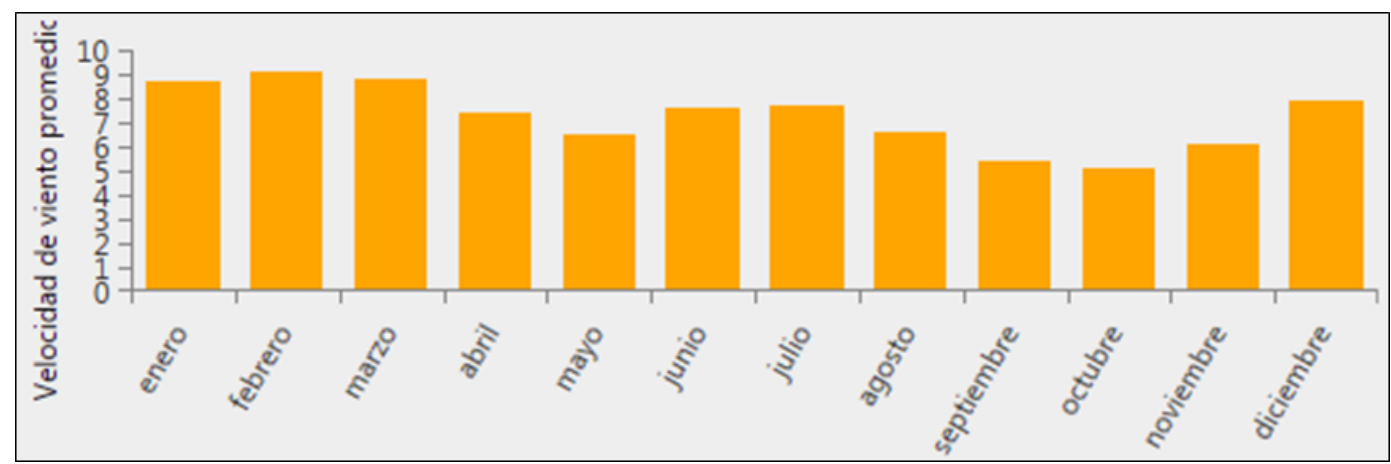

Fig. 3. Recurso eólico en HOMER de Puerto Bolívar, La Guajira. Promedio anual: 7.26 m/s. Fuente: autores.

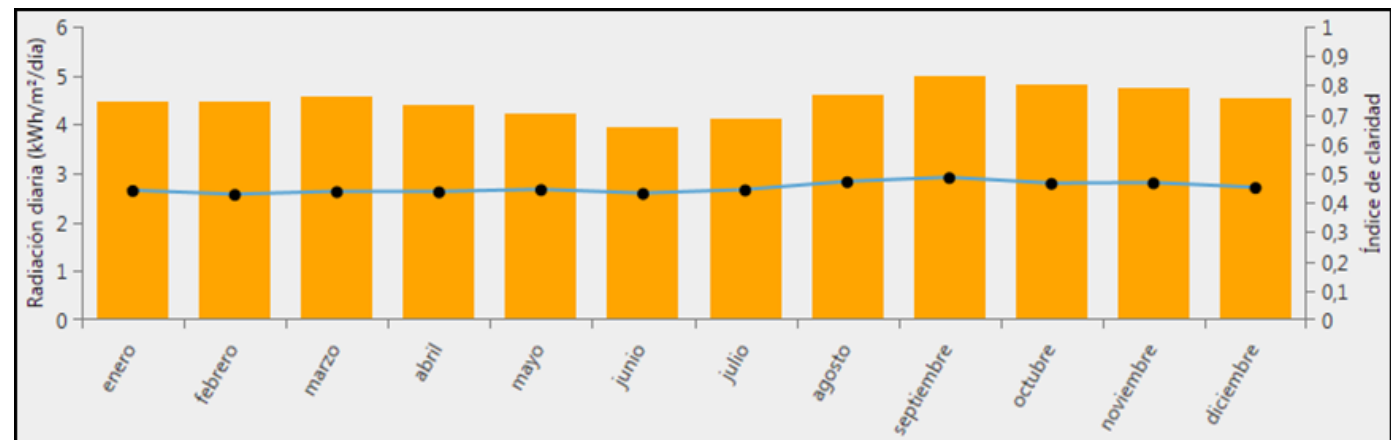

Fig. 4. Recurso solar en HOMER de La Pedrera, Amazonas. Promedio anual: 4.49 kWh/m2/día. Fuente: autores. 


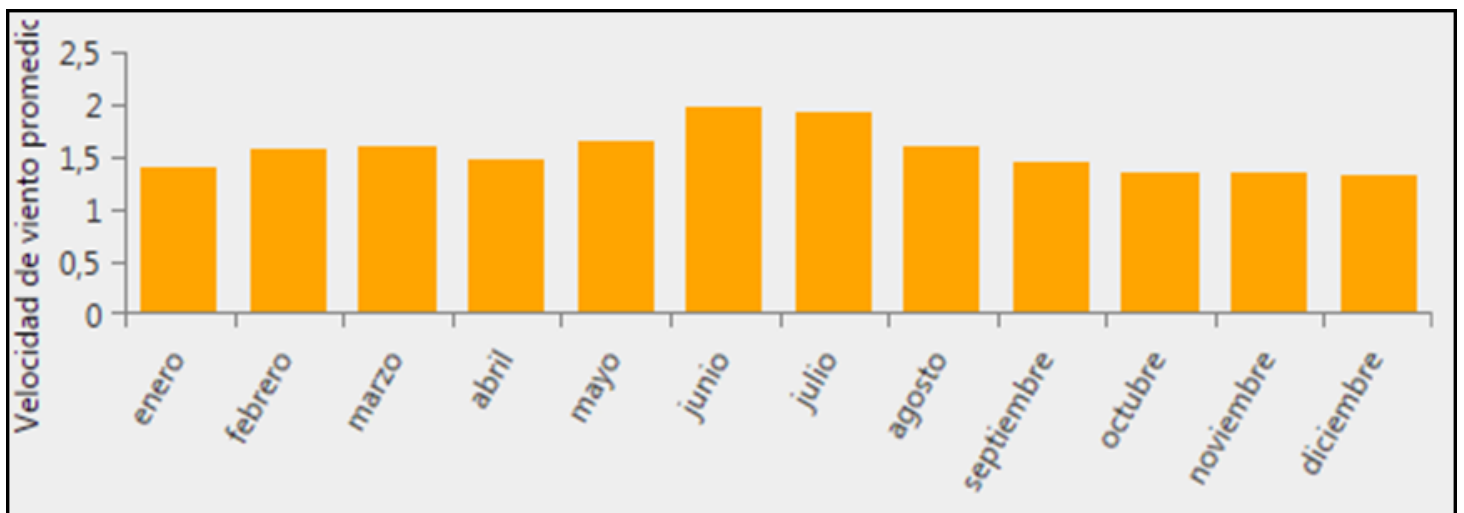

Fig. 5. Recurso eólico en HOMER de La Pedrera, Amazonas. Promedio anual: 1.56 m/s. Fuente: autores.

\section{SELECCIÓN Y DIMENSIONAMIENTO DE COMPONENTES}

Con base en la demanda energética y perfil de carga del poblado, se realiza el dimensionamiento de las tecnologías renovables y no renovables que integran el mix energético de la microrred, el cual se evalúa según su disponibilidad y sus costos. El proceso de dimensionamiento se basa en un procedimiento similar documentado en [20].

\subsection{Generador Diésel}

Esta fuente es comúnmente usada en los poblados de las ZNI para proveer el suministro energético. Se caracteriza por ser una fuente confiable y constante, sin embargo, los costos por transporte de combustible diésel y mantenimiento en las ZNI, hacen de esta fuente una opción costosa, además de ser contaminante. Se establece este generador para operar en el horario nocturno, de 6 p.m. a 12 a.m., con una capacidad de $55 \mathrm{~kW}$. El exceso de energía generada en su operación será empleado para cargar las baterías.

\subsection{Generador fotovoltaico e inversores}

Los generadores fotovoltaicos se encargan de transformar la energía proveniente del sol en energía eléctrica. Su principal ventaja es el uso de la energía renovable e inagotable del sol, además de ser una fuente no contaminante $\left(e n \mathrm{CO}_{2}\right)$ y silenciosa. Como desventajas, depende en gran medida de la disponibilidad de la radiación solar, además del impacto paisajístico y uso de grandes extensiones de suelo para su instalación, dependiendo de la capacidad a instalar.

Para el estudio, la capacidad de este generador se dimensiona con el objetivo de cubrir la demanda diaria. Se establece que el generador solar posee un factor de reducción de 90 \% para tener en cuenta las variaciones en los módulos debido a la temperatura. De acuerdo con el perfil de carga (Fig. 1), se tiene que el pico máximo se encuentra en $35.2 \mathrm{~kW}$, por tanto, un generador solar de $40 \mathrm{~kW}$ es el indicado para atender la demanda, teniendo en cuenta el factor de reducción. El generador se organiza en 8 arreglos, cada uno con 20 paneles de $250 \mathrm{~W}$ en serie para obtener una capacidad por arreglo de $5 \mathrm{~kW}$, de los cuales, cada uno posee un inversor de la misma capacidad con una eficiencia del $96.9 \%[21]$.

\subsection{Baterías}

El sistema de almacenamiento se conforma por un banco de baterías, el cual atiende la demanda energética en el día conjuntamente con el generador fotovoltaico. El estado de carga de las baterías o SOC ("State of Charge" por sus siglas en inglés) se establece en $90 \%$, el cual debe ser alcanzado nuevamente con 
los excedentes producidos por el generador diésel cuando este se encargue de la demanda nocturna [20].

La capacidad de las baterías se diseña bajo los supuestos de atender la demanda diaria de 6 a.m. a 6 p.m., con 2 días de autonomía, $80 \%$ de profundidad de descarga y eficiencia "roundtrip" del $86 \%$ [20]. Con base a la información que suministra el perfil de carga (Fig. 1), la energía a suplir en ese lapso es de aproximadamente $281.25 \mathrm{kWh}$. Empleando la expresión (1) se calcula la cantidad total de energía a contener en el banco de baterías, la cual relaciona matemáticamente los días de autonomía del banco (Da), la energía a suplir (Es) y el porcentaje de profundidad de descarga expresado en unidades decimales (Pd) [20].

$E_{\text {acum }}=\frac{\left(D_{a}\right)\left(E_{s}\right)}{P_{d}}$

Realizando los cálculos para el caso de estudio, se obtiene un valor de Eacum= $703.13 \mathrm{kWh}$. Se elige una batería comercial (2V-600Ah) de $1.2 \mathrm{kWh}$ de capacidad y se divide la Eacum entre esta capacidad para obtener el número aproximado de baterías que conformarán el banco. Realizado este cálculo, se tiene un valor aproximado de 586 baterías. Debido a que la configuración de la microrred se diseña trifásica, se distribuye de manera uniforme el número óptimo de baterías, el cual corresponde a 576, para ser organizadas en 192 baterías por fase y cada fase por 8 series de 24 baterías (48V por fase).

\subsection{Inversor-Cargador}

Este dispositivo se encarga de realizar la carga de las baterías con los excedentes provenientes de los generadores y la descarga de las mismas en el horario diurno, cuando el banco de baterías soporta al generador fotovoltaico en la atención de la demanda. Se dimensiona para cubrir el pico de demanda diaria, entre las 6 a.m. y
6 p.m., con un factor de seguridad de 1.2 [20]. Este factor se tiene en cuenta para prever cualquier exceso que supere el pico de demanda diaria. A partir de la información suministrada por el perfil (Fig. 1), el pico de demanda se encuentra en $27.46 \mathrm{~kW} \times 1.2=32.95 \approx 33 \mathrm{~kW}$. Por capacidades comerciales, se establece la implementación de 6 convertidores de 5 $\mathrm{kW}$, los cuales se conectarán por parejas en paralelo por cada fase de la microrred.

\subsection{Celda de Combustible}

La CC es una fuente generadora que emplea el hidrógeno como combustible y el oxígeno del aire como oxidante, sin el empleo de la combustión para la generación eléctrica, con la ventaja de que su único subproducto del proceso es agua y calor, es decir libre de emisiones contaminantes.

Se integra al mix energético una celda de combustible con capacidad de $33 \mathrm{~kW}$ como unidad de respaldo. La capacidad máxima se diseña de acuerdo con el pico máximo de consumo según el perfil (Fig. 1), entre las 12 a.m. y las 6 p.m. que es de $27.46 \mathrm{~kW}$. Debido a que su energía es entregada en DC y con el propósito de integrarla al bus AC por cuestiones técnicas del seguimiento de carga y eficiencia, se contempla un inversor dedicado de la misma capacidad (33 kW) para la conexión al bus AC.

\subsection{Aerogeneradores}

Estos equipos se encargan de transformar la energía cinética del viento en energía eléctrica a través de un alternador accionado por una turbina. Es una tecnología que utiliza una fuente renovable de energía, libre de contaminación, pues no produce emisiones. Esta fuente es altamente dependiente del recurso eólico en la zona donde se instale para ser viable su instalación. 
Para el estudio se integran dos tipos de aerogeneradores: $2 \mathrm{~kW} \quad$ y $20 \mathrm{~kW}$ de capacidad. Estas capacidades se eligen con el propósito de contrastar la viabilidad económica de las dos opciones, de acuerdo con la disponibilidad del recurso eólico en las dos ubicaciones del poblado, ya que con base en la información suministrada por las Fig. 3 y 5, con promedios de viento anuales de $7.26 \mathrm{~m} / \mathrm{s}$ y $1.56 \mathrm{~m} / \mathrm{s}$ para las ubicaciones de La Guajira y Amazonas respectivamente, existen niveles de velocidad que son insuficientes para un solo tipo de generador. Por ejemplo, según la curva de potencia del aerogenerador de $20 \mathrm{~kW}$ elegido, genera una potencia aproximada de $1.25 \mathrm{~kW}$ a partir de una velocidad de viento de $5 \mathrm{~m} / \mathrm{s}$ [22], lo cual no es posible con velocidades inferiores a esta, como se presenta en el recurso eólico de la Fig. 5 (promedio eólico anual de $1.56 \mathrm{~m} / \mathrm{s}$ ).

\section{ESTIMACIÓN DE COSTOS DE LAS TECNOLOGÍAS DE LA MICRORRED}

Para la obtención de los costos asociados a las tecnologías y al dimensionamiento propuesto, se presentan los valores individuales en dólares de acuerdo con la información suministrada por los fabricantes, distribuidores nacionales y extranjeros. Con respecto a la información suministrada por los proveedores internacionales, se incluye el sobrecosto de importación aproximado de $40 \%$. Cabe resaltar que la Ley 1715 de 2014 [2] contempla una exclusión del gravamen arancelario previo estudio y recomendación de la UPME (Unidad de Planeación Minero Energética) y la ANLA (Autoridad Nacional de Licencias Ambientales). En este estudio se considera el peor escenario, correspondiente a la no aprobación de la exclusión del gravamen, esto con el fin de hacer una comparación justa, ya que el combustible usado para el generador diésel no tiene ningún tipo de beneficio arancelario.
En los costos de cada tecnología se incluyen, además, los costos asociados al transporte por tonelada dentro del territorio nacional, tomando como base el establecido en [20], con un incremento gradual desde el año 2010 hasta el 2017 según el IPC (Índice de Precios al Consumidor) se tiene como resultado 521.94 US\$/ton. A pesar de que los medios de transporte de carga y las tarifas están determinados por la ubicación de los dos poblados, para este análisis se estableció emplear una sola tarifa de transporte, como estimativo general debido a la variedad de medios y costos.

Respecto a los costos de combustible, en este caso Diésel e hidrógeno, se incluye el costo aproximado del transporte de cada litro y kilogramo, al costo de cada combustible respectivamente, con base a valores establecidos en [23], con un incremento gradual desde el año 2013 hasta el 2017 según el IPC. Debido a que los costos de transporte de combustible varían tanto del lugar de destino, medio de transporte utilizado y tipo de combustible, en este estudio, se emplea una sola tarifa para cada uno, en ambas ubicaciones del poblado. La tarifa de cada combustible se basa en el valor de la máxima tarifa correspondiente existente en el país, basado en la información suministrada en [23], con el propósito de cubrir la mayor cantidad de posibilidades. El costo correspondiente del diésel a noviembre de 2017 está establecido en 0.71 US $\$ / L$, con un costo de transporte aproximado de 0.99 US $\$ / \mathrm{L}$, que da como resultado un costo total de $1.7 \mathrm{US} \$ / \mathrm{L}$. A partir de este valor, se determina una variación de sensibilidad en HOMER de 0.5 desde $1.7 \mathrm{US} \$ / \mathrm{L}$ hasta 2.7 US $\$ / L$ para el diésel. Para el costo del hidrógeno, se establece el precio de 1.74 US $\$ / \mathrm{kg}$, al cual se le adiciona el costo de transporte, que se toma como base el costo de transporte del Gas Licuado de Petróleo (GLP), con un incremento gradual desde el año 2013 hasta el 2017 según el IPC para el $\mathrm{kg}$ de hidrógeno, el cual fue de 
aproximadamente $\quad 1.22 \quad \mathrm{US} \$ / \mathrm{kg}$, obteniéndose un costo total de 3 US $\$ / \mathrm{kg}$. A partir de este valor, se determina una variación de sensibilidad en HOMER de 0.5 desde $3 \mathrm{US} \$ / \mathrm{kg}$ hasta $4 \mathrm{US} \$ / \mathrm{kg}$ para el hidrógeno. El valor del incremento en la variación de sensibilidad es un parámetro de libre elección. En el estudio se escogió un valor de 0.5 , con el objetivo de centrarse en valores relevantes de los costos de combustible, minimizando además el número de combinaciones posibles entre las dos variables de sensibilidad que incrementarían los cálculos para casos de optimización no relevantes en el análisis.

En la estimación de costos se incluyen los costos fijos de capital, que corresponden a obras civiles, cableado y demás costos relacionados con la instalación, como permisos o licencias. Se toma como base el costo establecido en [20], con un incremento gradual desde el año 2010 hasta el 2017 según el IPC. Para incluir estos costos en HOMER, se dividen en un $70 \%$ para el generador solar, $15 \%$ para las baterías y el $15 \%$ restante para los costos de la CC, la distribución de costos se realiza acorde a las obras civiles necesarias estimadas para cada componente, tales como estructuras metálicas, canalizaciones, compra y adecuación de terrenos para el generador solar, fundamentos de concreto y caseta para el banco de baterías y CC, similar a como se describe en [20].

Luego de realizar los respectivos cálculos de costos, y adecuarlos acorde a cómo deben ser ingresados en HOMER, se muestra en la Tabla 2 los resultados correspondientes, de manera similar a [20], referenciando el equipo comercial tenido en cuenta para el análisis.

\section{ESTIMACIÓN DE COSTOS DE LAS TECNOLOGÍAS DE LA MICRORRED}

Luego de implementar los distintos componentes en HOMER, se presenta en la Fig. 6 el esquema de la microrred a evaluar en el análisis económico.

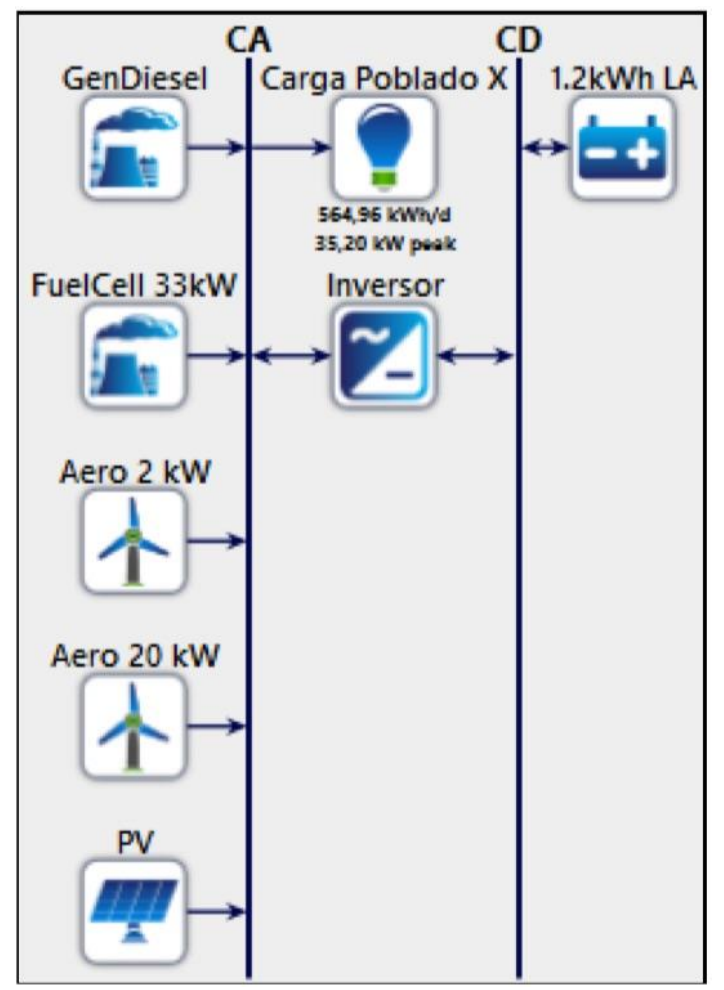

Fig. 6. Esquema de la microrred en HOMER. Fuente: autores. 
Análisis de factibilidad técnico-económico de microrredes que integran celdas de combustible en zonas no interconectadas de Colombia

Tabla 2. Costos y Parámetros de entrada en HOMER. Fuente: autores.

\begin{tabular}{|c|c|c|}
\hline Componente & Parámetros Entrada & \\
\hline Generador & Tamaño (kW) & 55 \\
\hline \multirow{2}{*}{$\begin{array}{l}\text { Diésel } \\
\text { KOHLER 55kW }\end{array}$} & Inversión (US\$/55kW) & $\$ 46.755$ \\
\hline & Reemplazos (US $\$ / 55 \mathrm{~kW})$ & $\$ 46.755$ \\
\hline \multirow[t]{2}{*}{ 55EOZCJ } & O\&M (US\$/hr) & $\$ 0,5$ \\
\hline & Vida útil (hr) & 15000 \\
\hline \multirow{2}{*}{ Módulos PV YINGLI SOLAR } & Tamaño (kWp) & 40 \\
\hline & Módulos: Costos de Capital(US\$/kWp) & $\$ 1.622$ \\
\hline \multirow{2}{*}{ YGE 60CELL $250 \mathrm{~W}+$} & Inversores: Costos de Capital(US $\$ / \mathrm{kW})$ & $\$ 503$ \\
\hline & $\begin{array}{l}\text { Reemplazos: Módulos + Inversores (US } \$ / 1 \\
\mathrm{kWp} \text { ) }\end{array}$ & $\$ 1.931$ \\
\hline FRONIUS PRIMO & Módulos: Vida útil (yr) & 25 \\
\hline $5.0-1$ & Inversores: Vida útil (yr) & 15 \\
\hline \multirow{3}{*}{$5 \mathrm{~kW}$} & O\&M (US\$/yr) & $\$ 35$ \\
\hline & Derating factor (\%) & 90 \\
\hline & Inclinación $\left(^{\circ}\right)$ & 6 \\
\hline Baterías & Cantidad (Baterías) & 576 \\
\hline MTEK & Inversión (US\$/bat 1.2kWh) & $\$ 260$ \\
\hline MT26000 & Reemplazos (US\$/bat 1.2kWh) & $\$ 211$ \\
\hline \multirow{2}{*}{ 2V600Ah } & O\&M (US\$/yr) & 0 \\
\hline & Eficiencia carga/descarga (\%) & 86 \\
\hline \multirow{8}{*}{$\begin{array}{l}\text { Inversor - cargador } \\
\text { VICTRON } \\
\text { QUATTRO } \\
\text { 48V 5kW }\end{array}$} & Tamaño (kW) & 30 \\
\hline & Inversión (US\$/kW) & $\$ 901$ \\
\hline & Reemplazos (US $\$ / \mathrm{kW})$ & $\$ 901$ \\
\hline & O\&M (US\$/yr) & 0 \\
\hline & Vida útil (yr) & 15 \\
\hline & Eficiencia inversor (\%) & 95 \\
\hline & $\begin{array}{l}\text { Capacidad relativa al } \\
\text { Inversor }(\%)\end{array}$ & 100 \\
\hline & Eficiencia rectificador (\%) & 95 \\
\hline \multirow{2}{*}{ Diésel } & Precio Diésel (US\$/lt) & $\$ 1,7$ \\
\hline & Sensibilidad incrementos de 0,5 hasta & $\$ 2,7$ \\
\hline \multirow[b]{2}{*}{ Hidrógeno } & Precio hidrógeno (US\$/kg) & $\$ 3,0$ \\
\hline & $\begin{array}{l}\text { Sensibilidad incrementos } \\
\text { de } 0,5 \text { hasta }\end{array}$ & $\$ 4,0$ \\
\hline \multirow{5}{*}{$\begin{array}{l}\text { Celda de Combustible } \\
\text { HYDROGENICS } \\
\text { HyPMTM HD30 } 33 \mathrm{~kW} \mathrm{+} \\
\text { Inversor WINDSUN } \\
\text { GC-238 } \\
33 \mathrm{~kW}\end{array}$} & Tamaño (kW) & 33 \\
\hline & Inversión (US\$/1kW) & $\$ 1274$ \\
\hline & Reemplazos (US\$/1 kW) & $\$ 1274$ \\
\hline & O\&M (US\$/hr) & $\$ 0,05$ \\
\hline & Vida útil (hr) & 10000 \\
\hline Aerogenerador & Cantidad (Aerogeneradores) & 1 \\
\hline AEOLOS & Inversión (US\$/aerogen) & $\$ 9.093$ \\
\hline WIND TURBINE & Reemplazos (US\$/aerogen) & $\$ 9.093$ \\
\hline \multirow[t]{2}{*}{$\mathrm{H}-2 \mathrm{~kW}$} & O\&M (US\$/yr) & $\$ 50$ \\
\hline & Vida útil (yr) & 25 \\
\hline
\end{tabular}


Análisis de factibilidad técnico-económico de microrredes que integran celdas de combustible en zonas no interconectadas de Colombia

\begin{tabular}{llr}
\hline & Cantidad (Aerogeneradores) & 1 \\
Aerogenerador & Inversión (US\$/aerogen) & $\$ 77.082$ \\
WIND TURBINE & Reemplazos (US\$/aerogen) & $\$ 77.082$ \\
H- $20 \mathrm{~kW}$ & O\&M (US\$/yr) & $\$ 50$ \\
& Vida útil (yr) & $\$ 20$ \\
\hline & Tasa de descuento (\%/yr) & 12 \\
Parámetros & Tasa esperada de inflación (\%) & 2 \\
Económicos & Ciclo de vida del proyecto (yr) & 20 \\
& Costos Fijos de O\&M (US\$/yr) & $\$ 1.992,48$ \\
& Costos fijos de Capital (US\$) & $\$ 211.730$ \\
\hline
\end{tabular}

A manera de resumen, la Fig. 7 presenta el procedimiento general de implementación del modelo de la microrred en HOMER, luego de dimensionar y calcular los costos respectivos de los componentes. Aunque el orden en que se implementan los pasos es libre, se propone dicho esquema que ordena en secuencia los principales parámetros a tener en cuenta. Como primer paso se establece la ubicación geográfica del proyecto a través de la ventana principal del software, para luego proceder a descargar la información relacionada con los recursos renovables desde la base de datos de HOMER, los cuales quedan completamente determinados por la localización del proyecto. Como siguiente paso, se procede a implementar el perfil de carga a satisfacer mediante la microrred. En este apartado, HOMER ofrece distintas plantillas para la configuración del perfil, tales como perfil residencial, comercial, industrial y comunidad, que se escalan a las necesidades requeridas. Para este estudio, se implementa un perfil de carga propio a partir de la plantilla en blanco que ofrece el software, con el fin de evaluar los componentes de la microrred ante una demanda específica del caso de estudio, perfil que se replica para todos los meses del año dentro de HOMER.
Seguidamente, se procede a la implementación de cada componente de la microrred y los aspectos económicos del proyecto. En la Fig. 7, se enumera cada parámetro necesario a configurar en los componentes, empleando la información calculada en la Tabla II y la información técnica proporcionada por los fabricantes. Como penúltimo paso, se implementa las variables de sensibilidad que se requiere evaluar en HOMER, como las variaciones sobre los costos de combustible, los recursos renovables, costos en los componentes, entre otros.

Finalmente, se lleva a cabo la ejecución de la simulación, la cual presenta como resultado, las distintas configuraciones viables de los componentes de la microrred frente a cada variable de sensibilidad. Esta información es presentada de acuerdo con los siguientes parámetros: VPN, $\$ / \mathrm{kWh}$, costos de inversión inicial, horas de operación de los componentes, entre otros, además de presentar por cada configuración óptima de la microrred, toda la información detallada por componente, producción eléctrica, consumo de combustible, emisiones y otros parámetros importantes a lo largo de la evaluación del proyecto. 
Análisis de factibilidad técnico-económico de microrredes que integran celdas de combustible en zonas no interconectadas de Colombia

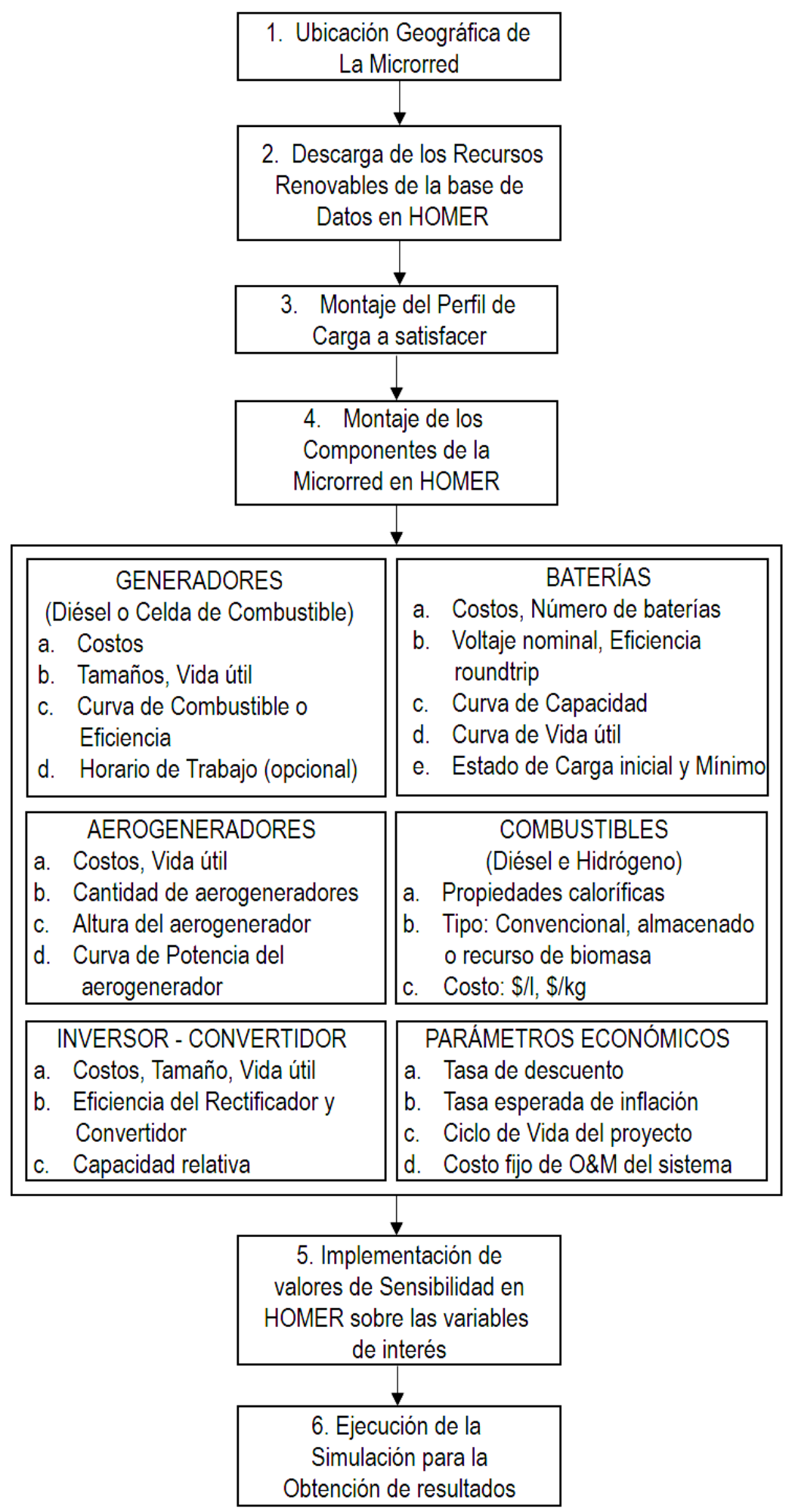

Fig. 7. Procedimiento general de implementación de la microrred en HOMER. Fuente: autores. 


\section{ANÁLISIS DE RESULTADOS - IMPACTO DE LAS CELDAS DE COMBUSTIBLE EN LAS MICRORRED}

Esta sección presenta los resultados de simulación obtenidos para el sistema de la microrred con y sin el efecto de las CC, a lo largo del ciclo de vida del proyecto. En los resultados, se presenta el comparativo de las configuraciones técnicamente óptimas frente a cada valor de la variable de sensibilidad, donde además se ilustran las variables relacionadas con el VPN ("Net Present Cost" - NPC por sus siglas en inglés), el costo nivelado de la energía $(\$ / \mathrm{kWh})$ ("Cost Of Energy" - COE por sus siglas en inglés), los costos de operación, inversión inicial y las variables relacionadas con el uso del generador diésel o la CC: horas de operación, consumo de combustible y costo del combustible.

\subsection{Resultados sin Celda de Combustible}

En la Fig. 8 se presentan los resultados de simulación en el poblado de Puerto Bolívar sin considerar la $\mathrm{CC}$ en el mix energético, donde se refleja una demanda del generador diésel de 2166 horas para suplir la carga eléctrica determinada ante un costo de combustible de $1.7 \$ / \mathrm{L}$. Adicionalmente, se evidencia un COE de $\$ 0.717$ y un NPC de $\$ 1.27 \mathrm{M}$ para la solución con menor costo de combustible, debido a la integración de diferentes tecnologías renovables que incrementan las inversiones de la solución. Así mismo, la Fig. 9 presenta la distribución porcentual de la generación eléctrica donde se evidencia que el $36 \%$ de la energía producida proviene de los paneles fotovoltaicos $y$ el $36.9 \%$ proviene del generador diésel, lo que ocasiona un consumo de combustible fósil que se refleja en la liberación de 69.6 toneladas de dióxido de carbono a la atmosfera por año, por lo tanto, dicha solución presenta una alta dependencia de combustibles fósiles para garantizar su viabilidad técnica al igual que incrementa los costos de mantenimiento debido al alto consumo de diésel.

El análisis del poblado La Pedrera se presenta en la Fig. 10, donde se evidencian las soluciones óptimas de acuerdo con los diferentes valores de costo de combustible y los costos asociados a la instalación. Se observa que las soluciones óptimas reportadas presentan nula dependencia de las tecnologías eólicas, acorde a la poca disponibilidad de los recursos, como lo presenta la Fig. 5. Estos resultados sugieren el uso principal del Diésel como alternativa para el suministro eléctrico de la población en particular, este análisis se presenta en la Fig. 11 donde se evidencia una alta dependencia de este tipo de tecnología (73.5\%), que igualmente se refleja en una alta liberación de dióxido de carbono a la atmosfera (131.5 toneladas por año).

\begin{tabular}{|c|c|c|c|c|c|c|c|c|c|c|c|c|c|c|c|c|c|c|}
\hline \multirow{2}{*}{$\begin{array}{l}\text { Sensitivity } \\
\text { Diesel } \\
\text { Fuel Price } \nabla \\
(\$ / L)\end{array}$} & \multicolumn{11}{|c|}{ Architecture } & \multicolumn{4}{|c|}{ Cost } & \multicolumn{3}{|c|}{ GenDiesel } \\
\hline & 4 & & t & +5 & 㧢 & $\boldsymbol{\Sigma} \underset{(\mathrm{kW})}{\mathrm{PV}} \nabla$ & Aero $2 \mathrm{~kW} \nabla$ & Aero $20 \mathrm{~kW} \nabla$ & $\begin{array}{c}\text { GenDiesel } \\
(\mathrm{kW})\end{array}$ & $1.2 \mathrm{kWh} L \mathrm{LA}$ & $\begin{array}{c}\text { Inversor } \\
(\mathrm{kW})\end{array} \nabla$ & $\underset{(\$)}{C O E} \nabla$ & $\underset{(\$)}{\mathrm{NPC}} \mathbf{i} \nabla$ & $\begin{array}{c}\text { Operating cost } \\
(\$)\end{array}$ & $\begin{array}{c}\text { Initial capital } \\
(\$)\end{array}$ & Hours $\nabla$ & $\begin{array}{l}\text { Fuel } \nabla \\
\text { (L) }\end{array}$ & $\begin{array}{l}\text { Fuel Cost } \\
(\$)\end{array}$ \\
\hline 1,70 & & $m 1$ & 个个 & 1 & 瞳 $\tilde{\varepsilon}$ & (2) 40,0 & 1 & 1 & 55,0 & 576 & 30,0 & $\$ 0,717$ & $\$ 1,27 \mathrm{M}$ & $\$ 78.371$ & $\$ 598.690$ & 2.166 & 26.413 & 44.902 \\
\hline 2,20 & & $\Psi 1$ & 个个 & $1=$ & 国 & च 40,0 & 1 & 1 & 55,0 & 576 & 30,0 & $\$ 0,787$ & $\$ 1,40 \mathrm{M}$ & $\$ 92.964$ & $\$ 598.690$ & 2.085 & 26.091 & 57.400 \\
\hline 2,70 & & $m$ & $\uparrow \uparrow$ & 15 & 8 & च 40,0 & 1 & 1 & 55,0 & 576 & 30,0 & $\$ 0,851$ & $\$ 1,51 \mathrm{M}$ & $\$ 106.020$ & $\$ 598.690$ & 2.085 & 26.094 & 70.454 \\
\hline
\end{tabular}

Fig. 8. Resultados óptimos Puerto Bolívar, La Guajira sin CC. Fuente: autores. 
Análisis de factibilidad técnico-económico de microrredes que integran celdas de combustible en zonas no interconectadas de Colombia

\begin{tabular}{|l|ll|}
\hline Production & $\mathrm{kWh} / \mathrm{yr}$ & $\%$ \\
\hline PV & 86.433 & 36,0 \\
\hline GenDies & 88.741 & 36,9 \\
Aero $2 \mathrm{~kW}$ & 5.682 & 2,36 \\
Aero $20 \mathrm{~kW}$ & 59.452 & 24,7 \\
Total & 240.308 & 100 \\
\hline
\end{tabular}

\begin{tabular}{|l|ll|}
\hline Quantity & Value & Units \\
\hline Carbon Dioxide & 69.554 & $\mathrm{~kg} / \mathrm{yr}$ \\
\hline Carbon Monoxide & 172 & $\mathrm{~kg} / \mathrm{yr}$ \\
Unburned Hydrocarbons & 19,0 & $\mathrm{~kg} / \mathrm{yr}$ \\
Particulate Matter & 12,9 & $\mathrm{~kg} / \mathrm{yr}$ \\
Sulfur Dioxide & 140 & $\mathrm{~kg} / \mathrm{yr}$ \\
Nitrogen Oxides & 1.532 & $\mathrm{~kg} / \mathrm{yr}$ \\
\hline
\end{tabular}

Fig. 9. Generación de energía y emisión de gases contaminantes - Puerto Bolívar, La Guajira sin CC. Fuente: autores.

\begin{tabular}{|c|c|c|c|c|c|c|c|c|c|c|c|c|c|c|c|c|c|}
\hline \multirow{2}{*}{$\begin{array}{l}\text { Sensitivity } \\
\begin{array}{|c|}\text { Diesel } \\
\text { Fuel Price } \nabla \\
(\$ / L)\end{array} \\
\end{array}$} & \multicolumn{10}{|c|}{ Architecture } & \multicolumn{4}{|c|}{ Cost } & \multicolumn{3}{|c|}{ GenDiesel } \\
\hline & $\triangle$ & $m+$ & $1+$ & E & 国 & z & $\begin{array}{c}\mathrm{PV} \\
(\mathrm{kW})\end{array}$ & $\begin{array}{c}\text { GenDiesel } \\
(\mathrm{kW})\end{array}$ & $1.2 \mathrm{kWh}$ LA $\nabla$ & $\begin{array}{c}\text { Inversor } \\
(\mathrm{kW})\end{array}$ & $\underset{(\$)}{\mathrm{COE}} \bullet$ & $\underset{(\$)}{\mathrm{NPC}} \bullet$ & $\begin{array}{c}\text { Operating cost } \\
(\$)\end{array}$ & $\begin{array}{c}\text { Initial capital } \\
\text { (\$) }\end{array}$ & Hours $\nabla$ & ${ }_{(L)}^{\text {Fuel }} \nabla$ & $\begin{array}{l}\text { Fuel Cost } \\
\text { (\$) }\end{array}$ \\
\hline 1,70 & & $m$ & & E & 睛 & च 4 & 40,0 & 55,0 & 576 & 30,0 & $\$ 0,928$ & $\$ 1,65 \mathrm{M}$ & $\$ 131.099$ & $\$ 520.275$ & 4.198 & 49.939 & 84.896 \\
\hline 2,20 & & 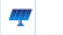 & & E & 目的 & z 4 & 40,0 & 55,0 & 576 & 30,0 & $\$ 1,05$ & $\$ 1,87 \mathrm{M}$ & $\$ 156.669$ & $\$ 520.275$ & 3.734 & 47.272 & 103.999 \\
\hline 2,70 & & $m$ & & th & 国 & z 4 & 40,0 & 55,0 & 576 & 30,0 & $\$ 1,17$ & $\$ 2,08 \mathrm{M}$ & $\$ 180.971$ & $\$ 520.275$ & 3.586 & 46.444 & 125.399 \\
\hline
\end{tabular}

Fig. 10. Resultados óptimos La Pedrera, Amazonas sin CC. Fuente: autores.

\begin{tabular}{|l|l|l|}
\hline Production & $\mathrm{kWh} / \mathrm{yr}$ & $\%$ \\
\hline PV & 58.663 & 26,5 \\
GenDies & 162.615 & 73,5 \\
Total & 221.278 & 100 \\
\hline
\end{tabular}

\begin{tabular}{|l|ll|}
\hline Quantity & Value & Units \\
\hline Carbon Dioxide & 131.506 & $\mathrm{~kg} / \mathrm{yr}$ \\
Carbon Monoxide & 325 & $\mathrm{~kg} / \mathrm{yr}$ \\
Unburned Hydrocarbons & 36,0 & $\mathrm{~kg} / \mathrm{yr}$ \\
Particulate Matter & 24,5 & $\mathrm{~kg} / \mathrm{yr}$ \\
Sulfur Dioxide & 264 & $\mathrm{~kg} / \mathrm{yr}$ \\
Nitrogen Oxides & 2.896 & $\mathrm{~kg} / \mathrm{yr}$ \\
\hline
\end{tabular}

Fig. 11. Generación de energía y emisión de gases contaminantes - La Pedrera, Amazonas sin CC. Fuente: autores.

\subsection{Resultados con Celda de Combustible}

De manera similar a la anterior, en la Fig. 12 y Fig. 13 se presentan los resultados incluyendo la $\mathrm{CC}$ como una nueva fuente energética dentro de la microrred, para el poblado de Puerto Bolívar. La Fig. 12 evidencia el análisis de la microrred ante diferentes valores de sensibilidad de combustible y costo del $\mathrm{kg}$ de hidrógeno. Se observa en los resultados que la CC se convierte en una alternativa viable frente a la dependencia del generador diésel, al remplazar el porcentaje de generación de dicha tecnología por energía generada por la $\mathrm{CC}$ (37.5\%). Igualmente, como se presenta en la Fig. 13, la reducción en horas de operación del generador diésel, se traduce en una disminución de emisiones de $\mathrm{CO} 2$ en la generación eléctrica de $0 \mathrm{~kg}$ por año, lo que reafirma el uso de este tipo de tecnologías para el cuidado del medio ambiente.

En el caso de La Pedrera (Fig. 14), los resultados obtenidos con el sistema sin considerar la CC (Fig. 10) son consecuentes con la adición de esta tecnología al mix energético. La disponibilidad de recursos ambientales limita la instalación a una generación a base de sistemas fotovoltaicos y CC para garantizar una viabilidad técnica. A pesar de la limitante, la solución reduce considerablemente el COE y el NPC en comparación con la microrred sin CC, ya que los costos de generación a base de hidrógeno son inferiores a los dependientes de combustibles fósiles. Así mismo, la Fig. 15 presenta la distribución porcentual de la generación eléctrica donde en comparación del porcentaje de generación 
Análisis de factibilidad técnico-económico de microrredes que integran celdas de combustible en zonas no interconectadas de Colombia

de la solución sin considerar CC (73.5 \%) se remplaza por $72.1 \%$ al considerar una tecnología basada en hidrogeno, lo que genera una reducción a cero emisiones de gases contaminantes a la atmosfera.

\begin{tabular}{|c|c|c|c|c|c|c|c|c|c|c|c|c|c|c|c|c|c|c|c|c|}
\hline \multicolumn{2}{|r|}{ Sensitivity } & \multicolumn{12}{|c|}{ Architecture } & \multicolumn{4}{|c|}{ Cost } & \multicolumn{3}{|c|}{ CC } \\
\hline $\begin{array}{l}\text { Diesel } \\
\text { Fuel Price } \nabla \\
(\$ / L)\end{array}$ & $\begin{array}{l}\text { Stored Hydrogen } \\
\text { Fuel Price } \\
(\$ / \mathrm{kg})\end{array}$ & $\nabla \triangle$ & $m$ & $\uparrow$ & $\uparrow$ & $E$ & E & 58 & ( & $\begin{array}{c}\mathrm{PV} \\
(\mathrm{kW})\end{array}$ & Aero $2 \mathrm{~kW} \nabla$ & Aero $20 \mathrm{~kW} \nabla$ & ${ }_{(\mathrm{kW})}^{\mathrm{CC}} \nabla$ & $\underset{(\$)}{\mathrm{COE}} \mathbf{P}$ & $\underset{(\$)}{\mathrm{NPC}} \bullet \nabla$ & $\underset{(\$)}{\text { Operating cost }}$ & $\begin{array}{c}\text { Initial capital } \\
(\$)\end{array}$ & Hours $\nabla$ & $\begin{array}{l}\text { Fuel } \nabla \\
(\mathrm{kg})\end{array}$ & $\begin{array}{c}\text { Fuel Cost } \\
(\$)\end{array}$ \\
\hline 1,70 & 3,50 & & $m$ & t & 个 & & E & 87 & ๘ & 40,0 & 1 & 1 & 33,0 & $\$ 0,568$ & $\$ 1,01 \mathrm{M}$ & $\$ 47.323$ & $\$ 601.737$ & 4.507 & 5.466 & 19.130 \\
\hline 1,70 & 3,00 & & 9 & 个 & 个 & & E & 대죠 & z & 40,0 & 1 & 1 & 33,0 & $\$ 0,555$ & $\$ 987.566$ & $\$ 44.714$ & $\$ 601.737$ & 4.526 & 5.468 & 16.404 \\
\hline 1,70 & 4,00 & & $m$ & t & t & & E & 8 & $\boldsymbol{z}$ & 40,0 & 1 & 1 & 33,0 & $\$ 0,580$ & $\$ 1,03 \mathrm{M}$ & $\$ 49.889$ & $\$ 601.737$ & 4.483 & 5.460 & 21.840 \\
\hline 2,20 & 3,50 & & $m$ & 小 & 小 & & E & 8 政 & ( & 40,0 & 1 & 1 & 33,0 & $\$ 0,568$ & $\$ 1,01 \mathrm{M}$ & $\$ 47.323$ & $\$ 601.737$ & 4.507 & 5.466 & 19.130 \\
\hline 2,20 & 3,00 & & 眾 & t & 个 & & $E$ & g & z & 40,0 & 1 & 1 & 33,0 & $\$ 0,555$ & $\$ 987.566$ & $\$ 44.714$ & $\$ 601.737$ & 4.526 & 5.468 & 16.404 \\
\hline 2,20 & 4,00 & & $m$ & 个 & 个 & & in & 87 & $\boldsymbol{z}$ & 40,0 & 1 & 1 & 33,0 & $\$ 0,580$ & $\$ 1,03 \mathrm{M}$ & $\$ 49.889$ & $\$ 601.737$ & 4.483 & 5.460 & 21.840 \\
\hline 2,70 & 3,50 & & $m$ & t & t & & E & 85 & z & 40,0 & 1 & 1 & 33,0 & $\$ 0,568$ & $\$ 1,01 \mathrm{M}$ & $\$ 47.323$ & $\$ 601.737$ & 4.507 & 5.466 & 19.130 \\
\hline 2,70 & 3,00 & & $m$ & t & t & & $E$ & 8 & 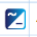 & 40,0 & 1 & 1 & 33,0 & $\$ 0,555$ & $\$ 987.566$ & $\$ 44.714$ & $\$ 601.737$ & 4.526 & 5.468 & 16.404 \\
\hline 2,70 & 4,00 & & 罚 & 个 & 个 & & E & 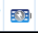 & z & 40,0 & 1 & 1 & 33,0 & $\$ 0,580$ & $\$ 1,03 \mathrm{M}$ & $\$ 49.889$ & $\$ 601.737$ & 4.483 & 5.460 & 21.840 \\
\hline
\end{tabular}

Fig. 12. Resultados óptimos Puerto Bolívar, La Guajira con CC. Fuente: autores.

\begin{tabular}{|l|ll|}
\hline Production & $\mathrm{kWh} / \mathrm{yr}$ & $\%$ \\
\hline PV & 86.433 & 35,6 \\
CC $33 \mathrm{~kW}$ & 91.094 & 37,5 \\
Aero $2 \mathrm{~kW}$ & 5.682 & 2,34 \\
Aero $20 \mathrm{~kW}$ & 59.452 & 24,5 \\
Total & 242.661 & 100 \\
\hline
\end{tabular}

\begin{tabular}{|c|c|c|}
\hline Quantity & Value & Units \\
\hline Carbon Dioxide & 0 & $\mathrm{~kg} / \mathrm{yr}$ \\
\hline Carbon Monoxide & 0 & $\mathrm{~kg} / \mathrm{yr}$ \\
\hline Unburned Hydrocarbons & 0 & $\mathrm{~kg} / \mathrm{yr}$ \\
\hline Particulate Matter & 0 & $\mathrm{~kg} / \mathrm{yr}$ \\
\hline Sulfur Dioxide & 0 & $\mathrm{~kg} / \mathrm{yr}$ \\
\hline Nitrogen Oxides & 0 & $\mathrm{~kg} / \mathrm{yr}$ \\
\hline
\end{tabular}

Fig. 13. Generación de energía y emisión de gases contaminantes - Puerto Bolívar, La Guajira con CC. Fuente: autores.

\begin{tabular}{|c|c|c|c|c|c|c|c|c|c|c|c|c|c|c|c|c|c|c|}
\hline \multicolumn{2}{|r|}{ Sensitivity } & \multicolumn{10}{|c|}{ Architecture } & \multicolumn{4}{|c|}{ Cost } & \multicolumn{3}{|c|}{ FuelCell } \\
\hline $\begin{array}{l}\text { Diesel } \\
\text { Fuel Price } \nabla \\
\text { (\$/L) }\end{array}$ & $\begin{array}{l}\text { Stored Hydrogen } \\
\quad \text { Fuel Price } \\
(\$ / \mathrm{kg})\end{array}$ & $\triangle \triangle$ & $m$ & 个 & 个 & in & E & 国 & $\approx$ & $\begin{array}{c}\mathrm{PV} \\
(\mathrm{kW})\end{array}$ & $\begin{array}{c}\text { FuelCell } \nabla \\
(\mathrm{kW})\end{array}$ & $\underset{(\$)}{\mathrm{COE}} \mathbf{( 1 )} \nabla$ & $\underset{(\$)}{\mathrm{NPC}}$ ( $\mathrm{P}$ & $\begin{array}{c}\text { Operating cost } \\
(\$)\end{array}$ & $\begin{array}{c}\text { Initial capital } \\
(\$)\end{array}$ & Hours $\nabla$ & $\begin{array}{l}\text { Fuel } \nabla \\
(\mathrm{kg})\end{array}$ & $\begin{array}{c}\text { Fuel Cost } \nabla \\
(\$)\end{array}$ \\
\hline 1,70 & 3,50 & & $m$ & & & & E & 재교 & $\approx$ & 40,0 & 33,0 & $\$ 0,540$ & $\$ 959.970$ & $\$ 76.041$ & $\$ 303.832$ & 7.161 & 9.102 & 31.857 \\
\hline 1,70 & 3,00 & & $m$ & & & & E & 주잠 & $\tilde{z}$ & 40,0 & 33,0 & $\$ 0,517$ & $\$ 920.553$ & $\$ 71.473$ & $\$ 303.832$ & 7.158 & 9.102 & 27.307 \\
\hline 1,70 & 4,00 & & $m$ & & & & E & 탁ㄱ & $\tilde{z}$ & 40,0 & 33,0 & $\$ 0,562$ & $\$ 999.429$ & $\$ 80.614$ & $\$ 303.832$ & 7.165 & 9.101 & 36.405 \\
\hline 2,20 & 3,50 & & $m$ & & & & E & 중 & $\approx$ & 40,0 & 33,0 & $\$ 0,540$ & $\$ 959.970$ & $\$ 76.041$ & $\$ 303.832$ & 7.161 & 9.102 & 31.857 \\
\hline 2,20 & 3,00 & & $m$ & & & & - & 8 政 & $\tilde{z}$ & 40,0 & 33,0 & $\$ 0,517$ & $\$ 920.553$ & $\$ 71.473$ & $\$ 303.832$ & 7.158 & 9.102 & 27.307 \\
\hline 2,20 & 4,00 & & $\Psi$ & & & & E & Eri & $\approx$ & 40,0 & 33,0 & $\$ 0,562$ & $\$ 999.429$ & $\$ 80.614$ & $\$ 303.832$ & 7.165 & 9.101 & 36.405 \\
\hline 2,70 & 3,50 & & $m$ & & & & E. & 재요 & $\approx$ & 40,0 & 33,0 & $\$ 0,540$ & $\$ 959.970$ & $\$ 76.041$ & $\$ 303.832$ & 7.161 & 9.102 & 31.857 \\
\hline 2,70 & 3,00 & & $m$ & & & & in & Ex马 & $\tilde{z}$ & 40,0 & 33,0 & $\$ 0,517$ & $\$ 920.553$ & $\$ 71.473$ & $\$ 303.832$ & 7.158 & 9.102 & 27.307 \\
\hline 2,70 & 4,00 & & 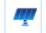 & & & & E & 죽ㅁ & 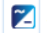 & 40,0 & 33,0 & $\$ 0,562$ & $\$ 999.429$ & $\$ 80.614$ & $\$ 303.832$ & 7.165 & 9.101 & 36.405 \\
\hline
\end{tabular}

Fig. 14. Resultados óptimos La Pedrera, Amazonas con CC. Fuente: autores.

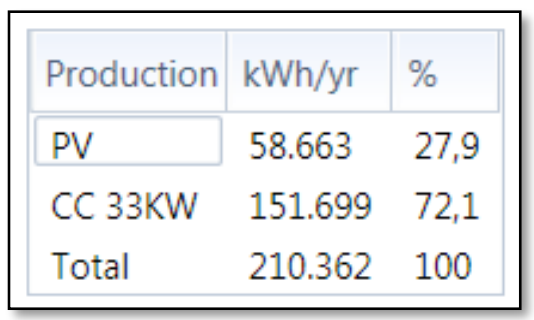

\begin{tabular}{|c|c|c|}
\hline Quantity & Value & Units \\
\hline Carbon Dioxide & 0 & $\mathrm{~kg} / \mathrm{yr}$ \\
\hline Carbon Monoxide & 0 & $\mathrm{~kg} / \mathrm{yr}$ \\
\hline Unburned Hydrocarbons & 0 & $\mathrm{~kg} / \mathrm{yr}$ \\
\hline Particulate Matter & 0 & $\mathrm{~kg} / \mathrm{yr}$ \\
\hline Sulfur Dioxide & 0 & $\mathrm{~kg} / \mathrm{yr}$ \\
\hline Nitrogen Oxides & 0 & $\mathrm{~kg} / \mathrm{yr}$ \\
\hline
\end{tabular}

Fig. 15. Generación de energía y emisión de gases contaminantes - La Pedrera, Amazonas con CC. Fuente: autores 
Análisis de factibilidad técnico-económico de microrredes que integran celdas de combustible en zonas no interconectadas de Colombia

\begin{tabular}{|c|c|c|c|c|}
\hline Caso & $\begin{array}{c}\mathrm{COE} \\
(\$ / \mathrm{kWh})\end{array}$ & $\begin{array}{l}\mathrm{NPC} \\
(\$)\end{array}$ & $\begin{array}{c}\text { Costo de Operación } \\
(\$ / y r)\end{array}$ & $\begin{array}{r}\text { Emisión } \\
\text { de } \mathrm{CO}_{2} \\
(\mathrm{~kg} / \mathrm{yr})\end{array}$ \\
\hline Puerto Bolívar sin CC & 0,85 & $1,51 \mathrm{M}$ & 78.371 & 69.554 \\
\hline Puerto Bolívar con CC & 0,58 & $1,03 \mathrm{M}$ & 49.889 & 0 \\
\hline La Pedrera sin CC & 1,17 & $2,08 \mathrm{M}$ & 180.971 & 131.506 \\
\hline La Pedrera con CC & 0,56 & 999.429 & 80.614 & 0 \\
\hline
\end{tabular}

Finalmente, la Tabla 3 presenta un paralelo del estudio realizado para ambas poblaciones, donde se comparan los $\mathrm{COE}$, $\mathrm{NPC}$, costos de operación y emisión de $\mathrm{CO}_{2}$ de las soluciones con mayor costo de combustible de diésel e hidrógeno, con el fin de analizar los peores casos de viabilidad económica. Es de notar, que las instalaciones basadas en $\mathrm{CC}$ presentan mejores resultados económicos en comparación con las que dependen de generadores diésel, con el agregado de una reducción a cero emisiones de $\mathrm{CO}_{2}$ a la atmosfera. Dicha comparación evidencia la pertinencia del uso de las CC en microrredes para zonas no interconectadas como una solución técnico-económica viable para el suministro de una demanda energética en dos poblaciones con diferentes recursos ambientales.

\section{CONCLUSIONES}

En el documento se presentó un análisis del impacto que las CC poseen sobre los costos de las microrredes a través del software HOMER, además de los beneficios relacionados con la reducción de las emisiones contaminantes.

Los resultados presentados ilustran que las CC a pesar de ser aún una tecnología costosa, compiten como una alternativa técnico-económica viable frente a las demás tecnologías renovables y no renovables en este tipo de aplicaciones, al reducir tanto los costos de las microrredes respecto al VPN y al costo nivelado de la energía. Igualmente, una solución basada en $\mathrm{CC}$ reduce la dependencia del generador diésel, que como se presenta en los casos de estudio lo reemplaza, eliminando las emisiones de $\mathrm{CO}_{2}$ por las actividades de generación eléctrica.

Adicionalmente, los resultados del trabajo permiten evidenciar que el COE de los sistemas que incluyen CC se ubica en promedio en 0,57 US $\$ / \mathrm{kWh}$, que, a pesar de ser un costo relativamente alto, permite reducir la dependencia de la generación diésel para las ZNI. Así mismo, este tipo de estudios fomenta la implementación de fuentes no convencionales como las CC y demás generadoras renovables, que cumplen con los objetivos trazados en el Plan de Desarrollo de las Fuentes de Energía No Convencionales, la Ley 1715 de 2014 y la Resolución 0186 de 2012 en lo que respecta a las ZNI. Es de notar, que dicho costo puede reducirse a través de incentivos tributarios o subsidios económicos sobre los consumidores basados en reglamentaciones futuras que planea el Gobierno Nacional para el 2018, para hacer este tipo de generación eléctrica más accesible a la población de estas zonas.

\section{AGRADECIMIENTOS}

Este trabajo fue financiado por la Universidad Nacional de Colombia, la Universidad Industrial de Santander, el Instituto Tecnológico Metropolitano y 
Análisis de factibilidad técnico-económico de microrredes que integran celdas de combustible en zonas no interconectadas de Colombia

Colciencias (Fondo Nacional de Financiamiento para Ciencia, la Tecnología y la Innovación Francisco José de Caldas) dentro de los proyectos MicroRENIZ-25439 (Code 1118-669-46197) y el proyecto P17211 financiado por el Instituto Tecnológico Metropolitano.

\section{REFERENCIAS}

[1] Consorcio Energético CORPOEMA, "Plan de Desarrollo para las Fuentes no Convencionales de Energía en Colombia (PDFNCE)," 2010.

[2] Congreso de la República, "Ley 1715," Colombia, 2014.

[3] Ministerio de Ambiente y Desarrollo Sostenible, Resolución 0186. Colombia, 2012, pp. 1-8.

[4] A. M. Eltamaly, M. A. Mohamed, M. S. AlSaud, and A. I. Alolah, "Load management as a smart grid concept for sizing and designing of hybrid renewable energy systems," Eng. Optim., vol. 49, no. 10, pp. 1813-1828, Oct. 2016.

[5] E. I. Zoulias et al., "Integration of hydrogen energy technologies in stand-alone power systems analysis of the current potential for applications," Renew. Sustain. Energy Rev., vol. 10, no. 5, pp. 432-462, Oct. 2006.

[6] L. Valverde, C. Bordons, and F. Rosa, "Integration of Fuel Cell Technologies in Renewable-Energy-Based Microgrids Optimizing Operational Costs and Durability," IEEE Trans. Ind. Electron., vol. 63, no. 1, pp. 167-177, Jan. 2016.

[7] E. I. Zoulias and N. Lymberopoulos, "Technoeconomic analysis of the integration of hydrogen energy technologies in renewable energy-based stand-alone power systems," Renew. Energy, vol. 32, no. 4, pp. 680-696, Apr. 2007.

[8] G. J. Dalton, D. A. Lockington, and T. E. Baldock, "Feasibility analysis of stand-alone renewable energy supply options for a large hotel," Renew. Energy, vol. 33, no. 7, pp. 1475-1490, Jul. 2008.

[9] R. H. Wolk, "Fuel cells for homes and hospitals," IEEE Spectr., vol. 36, no. 5, pp. 45-52, May 1999.

[10] D. Audring and G. Balzer, "Operating stationary fuel cells on power system and micro-grids," in 2003 IEEE Bologna Power Tech Conference Proceedings, 2003, vol. 4, pp. 97-102.

[11] A. K. Basu, A. Bhattacharya, S. P.
Chowdhury, S. Chowdhury, and P. A. Crossley, "Reliability study of a micro grid system with optimal sizing and placement of DER," in CIRED Seminar 2008: SmartGrids for Distribution, 2008, pp. 84-84.

[12] C. Wallmark and P. Alvfors, "Technical design and economic evaluation of a standalone PEFC system for buildings in Sweden," J. Power Sources, vol. 118, no. 1-2, pp. 358366, May 2003.

[13] Massimo Santarelli, Sara Macagno, and Michele Cali, "Design and analysis of standalone hydrogen energy systems with different renewable sources," Int. J. Hydrogen Energy, vol. 29, no. 15, pp. 15711586, Dec. 2004.

[14] FuelCell Energy, "High Efficiency Combined Heat \& Power (CHP)," FuelCell Energy, 2017. [Online]. Available: https://www.fuelcellenergy.com/supply/heatcooling/. [Accessed: 04-Dec-2017].

[15] T. Bayar, "Fuel cell CHP goes MW-scale in Germany," Decentralized energy, 2015. [Online]. Available: https://www.decentralizedenergy.com/articles/2015/08/fuel-cell-chpgoes-mw-scale-in-germany.html. [Accessed: 04-Dec-2017].

[16] Instituto de Planificación y Promoción de Soluciones Energéticas -IPSE, "Oportunidades actuales en el campo de las energías renovables en Colombia," Bogotá, 2015.

[17] Y. A. Muñoz Maldonado, "Optimización de recursos energéticos en zonas aisladas mediante estrategias de suministro y consumo," Universitat Politécnica de Valéncia, Valencia, 2012.

[18] Comisión de Regulación de Energía y Gas CREG, "Propuesta para remunerar la generación, distribución y comercialización de Energía Eléctrica en las ZNI," Bogotá, 2014.

[19] NASA, "NASA Surface meteorology and Solar Energy: HOMER Data," NASA Prediction Of Worldwide Energy Resources. [Online]. Available: https://eosweb.larc.nasa.gov/cgi-

bin/sse/homer.cgi?email=skip@larc.nasa.gov. [Accessed: 05-Apr-2018].

[20] Consorcio Energético CORPOEMA, "Formulacion de un plan de desarrollo para las fuentes no convencionales de energía en Colombia (PNFNCE)," Bogotá, 2010.

[21] FRONIUS PRIMO, "Technical Data Fronius Primo 5.0-1,” 2018.

[22] AEOLOS Wind Turbine, "Datasheet Aeolos$\mathrm{H}$ 20kW," wind turbinestar, 2018. [Online]. Available: https://en.wind-turbinemodels.com/turbines/1863-aeolos-aeolos-h- 
Análisis de factibilidad técnico-económico de microrredes que integran celdas de combustible en zonas no interconectadas de Colombia

20kw. [Accessed: 04-Dec-2017].

[23] Sistemas 2000 Ltda, "Determinación de

Inversiones y Gastos de Administración,

Operación y Mantenimiento para la actividad de Generación en Zonas No Interconectadas con Plantas Térmicas," 2013. 